University of Rhode Island

DigitalCommons@URI

Open Access Master's Theses

2008

\title{
An Examination of the Association of Sex and Gender and the Motives for Lying in Intimate Relationships
}

Anca Moraru

University of Rhode Island

Follow this and additional works at: https://digitalcommons.uri.edu/theses

\section{Recommended Citation}

Moraru, Anca, "An Examination of the Association of Sex and Gender and the Motives for Lying in Intimate Relationships" (2008). Open Access Master's Theses. Paper 1676.

https://digitalcommons.uri.edu/theses/1676

This Thesis is brought to you for free and open access by DigitalCommons@URI. It has been accepted for inclusion in Open Access Master's Theses by an authorized administrator of DigitalCommons@URI. For more information, please contact digitalcommons-group@uri.edu. 
AN EXAMINATION OF THE ASSOCIATION OF SEX AND GENDER AND THE MOTIVES FOR LYING IN INTIMATE RELATIONSHIPS BY ANCA MORARU

A THESIS SUBMITTED IN PARTIA FULFILLMENT OF THE REQUIREMENTS FOR THE DEGREE OF MASTER OF ARTS IN COMMUNICATION STUDIES 


\begin{abstract}
The current thesis examined the most common motives for lying in intimate relationships and the possible sex and gender differences in lying behavior. Student participants $(\mathrm{N}=250)$, aged between $19-25$ years old, at the University of Rhode Island, completed an anonymous questionnaire concerning motives for lying in intimate relationships. All participants were currently involved in a romantic relationship at the time of the study or had been involved in such a relationship in the recent past. Participants were asked to recall a prior serious deceptive experience with a relational partner. In the second part of the questionnaire students completed a Personal Attributes Questionnaire (Spence, Helmreich, \& Stapp 1974). This instrument is composed of twenty-four bipolar items describing personal characteristics, on each of which respondents are to rate themselves on a five-point scale.
\end{abstract}

The hypotheses for this thesis predicted sex and gender differences between men and women. After examining the relationship between biological sex and motivation for lying, results were not generally consistent with the hypotheses. The overall test of differences appears to show that there are no statistically significant sex. differences but rather gender differences between men and women in their motivation for lying in intimate relationships. 
Abstract ii

I. Statement of the Problem 1

II. Review of Pertinent Literature 4

- Intimate Relationships 4

- Lying and Deception $\quad 5$

- Lying in Relationships 7

- Motives for Lying 9

- Sex Differences in Lying Behavior 13

$\begin{array}{ll}\text { III. Theoretical Framework } & 16\end{array}$

IV. Statement of the Objective and Purpose of the Study 21

V. Method and Design/Procedure 25

- Sample 25

- Materials and Procedures 25

$\begin{array}{ll}\text { - Statistical Analyses } & 27\end{array}$

$\begin{array}{llr}\text { VI. Results } & 29\end{array}$

$\begin{array}{ll}\text { VII. Discussion } & 32\end{array}$

VIII. Limitation and Future Research 43

$\begin{array}{ll}\text { Appendix } & 46\end{array}$

Bibliography $\quad 51$ 


\section{Statement of the problem}

Why do intimate partners in a relationship lie to each other? Everybody wants a relationship that is built on openness, intimacy and trust, but in reality relationships don't always work that way. Husbands and wives, boyfriends and girlfriends, often lie to each other for different reasons, at different moments in time and in different ways. Partners in an intimate relationship lie to each other about their true feelings for each other, the feelings they have for others, and their level of commitment.

I am interested in the subject of lying in intimate relationships because lying in such relationships has been viewed as bad, immoral, and fundamentally wrong (Saxe, 1991). These negative views fail, however, to address situations in which lying is identified as an act of kindness and love, such as when a lie might spare another person suffering (Kaplar \& Gordon, 2004). Lying is a fact of social life rather than an extraordinary or unusual event. People tell lies to accomplish the most basic social interaction goals, such as influencing others, managing impressions, and providing reassurance and support. Each of these goals, when valued deeply, provides a motivation for lying (Kashy \& DePaulo, 1998).

DePaulo et al. (1996) reported that, on average, adult respondents reported telling one lie for every five social interactions in which they engaged, whereas participants in a college study reported telling two lies every day. According to this research, the content of these lies depended on the type of relationships (casual vs. close friend).

In their study Shusterman and Saxe (1990) sought out more than 50 undergraduate students who were involved in romantic relationships and asked them if 
they had ever lied to their partners. More than $85 \%$ reported that they had lied about another relationship. The interesting part was that almost all of the participants excused their deceit by saying that they told the lie to protect their partners.

Research to date has focused on people's ability to detect when lovers are lying. This research indicates that romantically involved people have a difficult time detecting deception because they tend to assume that the truth is being told (Levin \& McCornack, 1992). Scholars have also investigated what happens when deception is uncovered. Detecting deception often results in negative consequences especially when the lies uncovered are considered significant (McCornack \& Levin, 1990). Research also indicated that deception is relatively common in romantic dyads in comparison with other types of relationships. Moreover, research in these cases is inconsistent, with some studies indicating that deception is more frequent in romantic relationships than other types of relationships (Hample,1980: Lipard, 1988) and other studies showing just the opposite (DePaulo \& Kashy, 1998).

Romantic relationships are full of paradoxes. People put the most trust in the person who most likely to deceive them, and are most likely to deceive the person whom they love and trust the most. Partners in relationships will try to ignore and downplay any issues until they will have to confront the reality that intimate relationships are not perfect (Cole, 2005).

Research indicates that deception among romantic partners is more likely to be motivated by a concern for the relationship and for a partner when compared with the motives underlying the use of deception in other types of relationships (Metts, 1989). These comparative studies show that the frequency, motives and effects of 
deception varies across relationship types (strangers, acquaintances, friends, romantic partners) but they fail to provide sufficient information regarding partners' motives for lying in a romantic relationship and possible sex differences. The goal of this study is to address these issues by providing an in depth examination of the motives for lying in intimate relationships, and whether the motives are different for men and women. 
Review of the Pertinent Literature.

Intimate Relationships

In 2005, Cole suggested that intimate relationships provide many physical and emotional rewards. But, in order to attain the benefits that intimate relationships offer, it is essential for two people to know each other well. Romantic partners create intimacy by spending a lot of time together and being open with one other. Honesty and kindness are also important factors in creating intimacy. When people get closer to one another they tend to self-disclose more and thereby provide the partner with a great deal of information about themselves. Trust is the foundation of an enduring relationship, and trust grows with the belief that another is communicating in an honest, straightforward manner (Buller \& Burgoonn, 1996).

According to Miller, Mongeau, and Sleight (1986), as a relationship develops, the amount of information gained about a partner increases. In other words, general information is replaced with information specific to the partner's behavior. In the case of intimate partners, when the authenticity of one partner's communication is suspect, there exists a "store" of baseline information on the suspected partner's usual behavior. In this case, when deception is suspected between intimate partners, the suspecting partner has a store of both honest and deceptive behavior to be used in evaluating the behavior in question.

Research suggests that as individuals become more intimate they increasingly develop strict expectations regarding the honesty of their partners (Buller, 1998; McCornack \& Parks, 1986). As the intensity of feelings such as attachment, caring, and intimacy increases, so does the expectation that the partner will not lie. This 
expectation is described by researchers as a 'truth-bias" (Buller, 1998; McCornack \& Parks, 1986). This truth-bias creates the perfect opportunity for lovers to engage in deception because someone who is eager and willing to trust everything that has been said is the perfect victim (Cole, 2005).

An additional significant feature in a relationship with regard to detecting deception is a shared history with the partner. This creates two types of data: informational familiarity, which is background information about a partner, and behavioral familiarity, which includes knowledge of partner typical behavioral habits. Greater informational and behavioral familiarity should enable a receiver to better recognize a deception (Buller \& Burgoon, 1996).

Lying and Deception

Lying and lie detection are important parts of our communicative past, present, and future. Lies appear in many different forms under many different conditions (Knapp \& Comeda, 1979). People have been socialized to believe that lying is bad; we are taught and teach children, that lying is immoral and reprehensible. Yet, there are occasions when it is socially acceptable to lie (Saxe, 1991)

Buller (1996) defined deception as false information transmitted intentionally to support false beliefs and conclusions. Deception contains more than outright lies. It includes everything from white lies, to misdirection and avoidance, to equivocation and uncertainty, to camouflage and excluding relevant information. Deception is perceived by many as the only communication alternative available in some situations and may positively affect relational satisfaction (Cole, 2001; Hample, 1986).

Deceptions occur when communicators control the information contained in their 
message to transmit a meaning that departs from the truth as they know it (Buller \& Burgoon, 1996). Although some scholars such as Bok (1978) draw a distinction between deceiving and lying, for the purpose of this thesis these terms will be used interchangeably.

A deceptive message contains three components: the central deceptive message usually is verbal in nature; the ancillary message, which may be verbal or nonverbal, supports the deceptive message or protects the source in the event deception is detected; and unintentional behaviors, most of which are nonverbal and may serve to reveal deception (Buller \& Burgoon, 1996).

"Deceptive communication is any verbal or nonverbal message that one partner sends with the intent of leading the other partner to a belief or conclusion that the sender considers to be less than absolutely true or less than totally complete. A deceptive or misleading message may involve providing information that is either untrue or has been exaggerated or distorted in some manner, or may involve deliberately omitting information such that the partner is led to an incorrect conclusion or belief" (Boon \& McLeod, pp 467).

The nature and the consequences of a deceptive interaction vary from relatively harmless exchanges seeking to cheer up, add interest, or add humor in the relationship to destructive confrontations that threaten the stability of the relationship (Miller \& Stiff, 1992). From individuals who lie to a partner about other intimate relationships, to students and professors who create excuses for late papers, to salesmen and lawyers for whom deceptiveness can be a normatively authorized part of their daily work life, lying is not uncommon to anyone (Saxe, 1991). 


\section{Lying in Relationships}

Even though telling the truth and being understood are very important in a romantic relationship deception appears also, at least at times, to be needed, even in the best intimate relationships (Miller \& Stiff, 1992). Why do partners lie to each other? As Baxter (1990) demonstrated, close relationships create a wonderful opportunity for deception to occur and also they create the need. Romantic relationships offer individuals many rewards, but they also tend to be very constrictive, and individuals are no longer free to do what they want, when they want and with whom they want.

Relationship partners can be demanding, overly inquisitive and, as a result, telling the truth at times becomes more difficult, complicated and costly. Instead of arguing and fighting about every issue that may arise, people choose lying as a preferred option for dealing with the problems (Cole, 2001; Lippard, 1988). People find it hard to admit but lying to a romantic partner is a very effective way of maintaining the rewards they receive from the relationship while dealing with problems and limitations that such relationships impose (Cole, 2005).

How do partners decide when to lie to a lover? Research shows that most of the time individuals do not intentionally think about misleading a lover. Such decisions are managed by emotions and seem just to happen when the right situation presents itself. Often a sense of excitement, opportunity, and happiness can lead individuals to lie. On the other hand, a sense of fear, loss, and anxiety can prompt people to cover up and hide the deception. The decision to lie sometimes happens 
spontaneous, and sometimes with little thought, effort, or planning (McCornack, 1997; Lippard, 1988).

Trust is the basis of a lasting romantic relationship, and trust grows with the belief that another is communicating in a sincere way (Buller \& Burgoon, 1996). Relationships provide many rewards and because of that people are inclined to see their romantic partner in a positive light. Individuals place a lot of trust in their lovers, but while trust provides security and comfort, it also offers opportunity for deceit to occur (Cole, 2005). Research shows that as romantic partners become more trusting, they become more confident in but less accurate at, determining when truth is being told (Levine \& McCornack, 1992).

Individuals tend to assume sincerity on the part of their partner unless presented with significant conflicting evidence. Participants in a study by Miller, Mongeau and Sleight (1986) reported that little deception occurred in their intimate relationships they studied. They also found that some deception was necessary to keep the intimate relationships on an even keel.

Individuals involved in a romantic relationship are also interested in the relational outcome. To be trapped in a lie not only ruins the immediate objective of the deceit, it also affects the relationship itself. Being lied to by a stranger is often economically or professionally punishing, but being lied to by a romantic partner can be personally and relationally devastating. The relationship between intimate partners is usually severely altered if lying is detected. Of course the outcome depends on the significance of the lie and the importance that it has for a particular individual and relationship (Miller, Mongeau, \& Sleight, 1986). 
A person's willingness to maintain a relationship will at times depend upon whether the personal relationship is deemed important. If the relationship is important, it is to be expected that falsehoods will occur, some for the purpose of protecting and preserving the relationship itself.

Cole (2001) has suggested that most people involved in an intimate relationship believe that communication is the solution to their problems. Individuals believe that successful deceptions are difficult to achieve, that deceptive partners must expend a lot of effort, and that intimate partners can tell when a lover is lying. Cole states that none of these propositions is supported by evidence and rather, a romantic relationship is held together by a delicate balance of both candor and deceit. Both are critical to making an intimate relationship work.

Motives for Lying

For the purpose of this thesis "motives" will be defined as "a general disposition which will influence actions that are expected to lead to a particular kind of consequence or goal" (Atkinson, 1965, p 14).

Empirical studies of deception to date have explored a relatively narrow range of deceiver motives in intimate relationships and possible sex differences. Researchers have also emphasized what happens when deception is discovered. Detecting a deception usually results in negative emotional reactions, especially when the lies are considered to be important (McCornack \& Levine, 1990). Studies (Cole, 2001; Lipard, 1988) have also suggested that deception is more common in romantic relationships in comparison to other type of relationships. Moreover, related research indicates that deception in intimate relationships is more likely to be motivated by a concern for the 
relationship and for the partner, when compared with motives for lying in other types of relationships (Metts, 1989).

Lies are multiply determined and stem from various motives. Research studies have examined deception and its motives but such research is lacking in the context of testing the motives in intimate relationships and whether the motives are different for men and women. For example Turner et. al (1975) demonstrated that subjects involved in different dyadic encounters reported five different motives for lying :(i) to save face (either their own, the partner's or some third party's); (ii) to maintain, redirect or terminate social interaction; (iii) to avoid tension and conflict; (iv) to establish, maintain or maximize power or influence over another; and (v) to maintain, maximize or terminate an intimate relationship. Camden et al. (1984) found that subjects lied to satisfy their basic needs and affiliations and to protect their selfesteem.

Linskold and Walters (1983) developed a typology of motivations for lying in all kinds of interpersonal relationships that included altruistic, individualistic and exploitive motives such as: (i) telling a lie to save others from minor hurt, shame, or embarrassment; (ii) telling a lie to protect yourself or another from punishment or disapproval for a minor failing or blunder which hurts no one; (iii) telling a lie that will influence others in an official position in such a way that you will gain by their response to you, but they will not be harmed; (iv) telling a lie to make yourself appear better than you really are or to protect some gain, acquired some time ago, to which you were not really entitled; (v) telling a lie that, if successful, could cause others to do something that benefits you while, at the same time, harming themselves or causing 
themselves a loss; (vi) telling a lie that hurts someone else so that you can gain. Metts (1989) classified reasons for lying as being partner-focused, teller-focused, relationship-focused, or issue-focused.

Hample (1980) generally replicated the Turner et. al findings and concluded that motivations for lying fall into four categories: (i) benefits self; (ii) benefits the other participant in the interaction; (iii) benefits the relationship; and (iv) miscellaneous motivations.

Lippard (1988) found seven primary categories for deceptive behavior in interpersonal relationships, which included deception: (i) to achieve or defend resources; (ii) increase or decrease affiliation; (iii) protect self; (iv) protect another; (v) manipulate another; (vi) be humorous; (vii) and excuse one self.

Burgoon, Buller, and Woodall (1996) found six motives for lying, ranging from altruistic through individualistic to exploitative: (i) to save the partner from castigation or disapproval stemming from a minor mistake; (ii) to save the partner from minor hurt, shame or humiliation; (iii) to influence people in official positions to attain a reward for self and/or partner; (iv) to make one self look better or protect some gain received in the past to which one's may self not really be entitled; (v) to persuade the partner to do something for self-gain that will harm the partner or cause partner to lose some resource; and (vi) to hurt the partner for self gain.

People who have deceived a romantic partner often claim that they lied or withheld information in order to protect or avoid hurting the loved one. In a research study conducted by Shusterman \& Saxe (as cited in Saxe, 1991), 85\% of participants reported having lied to their current romantic partner about a past relationship, and 
almost all reported that they did so to protect their partner. Similarly, Metts (1989) found that the most commonly reported motive for lying to close others was to protect the person's feelings.

Cole (2001) reported three possible explanations for the use of lies in intimate relationships; reciprocal exchange of information, the desire to avoid punishment, and individuals" attachment beliefs. Cole used for this study 128 heterosexual couples who were required to have been dating for at least four months. His conclusion was that telling the truth is not always the best option.

Research on self-disclosure demonstrated that there are many risks associated with revealing information to others. People may react in an adverse, judgmental manner (Keely \& McKillop, 1996). Confidentiality in intimate relationships may not be as significant as a partner's reaction to undesirable information. Deception is most likely motivated by fear of a partner's disapproval.

In his study, Hample (1980) demonstrated that the decision to lie is not typically cued by some abstractable quality of the situation, but rather it appears that the specific situation cues a specific lie. Although the lies are obviously intentionally told, they may also be automatic responses and not necessarily reasoned or unambiguously motivated acts. Most of the times lies are motivated by a desire to benefit one's self. In fact, selfishly motivated lies outnumber all others by about two to one. As Linskold and Walters (1983) have noted, motives might affect a person's ability to lie successfully. 
Sex differences in Lying Behavior

"By all historical accounts, dissembling, equivocating, misdirection, and exaggeration have been part of the male and female condition for millennia" (Burgoon et al., 1998, p. 351). But does that mean men lie differently than women? The answer appears to be "yes". Prior research indicates that there may be sex differences in lying behavior but these studies did not concentrate solely on motivations in intimate relationships. Prior research has been concentrated in the domain of encoding and decoding deception, as well as nonverbal and verbal deception display. Sex difference findings have been mixed and inconclusive in these studies of deception. Moreover, no theoretical explanation of deceptive communication emphasizes sex as an important feature (Canary \& Dindia, 1998).

DePaulo (1979) indicates that, in spite of women's advantage in decoding nonverbal messages, women are usually poorer detectors of lies than are men. Moreover, research (Zuckerman, DePaulo, \& Rosenthall, 1981) has shown that female deception tends to be more readily detected than male deception.

Other research has shown that men and women may tell different kinds of lies depending on the nature of relationship (casual vs. friendship). For example, although men and women tell lies with the same frequency, women are more likely than men to tell other-oriented (polite) lies, especially to other women. In the case of men, selfcentered lies are more common than other-orientated (Gordon \& Miller, 2000). If men and women differ in the kinds of lies they tell to different targets, they also might be expected to differ in the motivation of lying. 
In a male-female (liar-listener) interaction, lies for self-esteem purposes were frequently used. Men tend to use lies to protect their image in the eyes of the female. In female -male interaction lies for affiliation purposes (frequently negative) were greatly used. For example women are more likely to have requests for undesired affiliation, such as being asked out on a date (Camden et al. 1984).

In a study on nonverbal behavior, Cody and O'Hair (1983) reported that only leg/ foot movements and hand gestures differentiated men from women. In general male liars employed more leg/foot movements than did female liars. When men liars had the chance to organize their answers, they tended to suppress these leg/foot movements as well as their gestures. In contrast, Donaghy, Grandpre, and Davis (1994) found that women who had not rehearsed their lies had the most foot/leg movement, whereas men had the least movement.

O'Hair and Cody (1987), in a research study on the vocal channel, showed that women had more vocal stress than men when lying, particularly when telling prepared lies. Men showed the same level of vocal stress for truthful and deceptive responses.

Tannen (1994) established that women tend to smile and gaze more frequently than men. Women also have more relaxed body positions and, in general, are more friendly and communicative. Their pleasant, immediate style may help women strategically create a favorable image when deceiving.

Camden et al. (1984) demonstrated that women use white lies more than do men to hide their true feelings from others (to avoid self-disclosure or to avoid interaction with others). Therefore, women use considerably more white lies to 
accomplish affiliation needs, but they frequently do so as a way of avoiding, rather than initiating, the affiliations. For example, women sometimes lie to avoid honoring a request (implicit or explicit) which would initiate undesired social interaction or to avoid continuation of undesired social interaction. Women are more likely to deceive to protect other's self-esteem, while men are more likely to lie to protect their own self-esteem. Women tell more of the kinds of lies that are intended to benefit other people, lies that are flattering, comforting, and protective (DePaulo et al, 1996). According to Lippard (1988), women are significantly more likely than men to lie to protect another's feelings ( $15.5 \%$ of all female deception vs. $9 \%$ of all male deception). 


\section{Theoretical Framework}

For a better understanding of the differences between male and female lying behavior, as well as motivations, it is important to take into consideration theories of sex difference. One of these theories which is biologically based is the theory of social sensitivity (Hall, 1978). According to this theory, women are genetically predisposed to greater social sensitivity. Several studies have shown that females are particularly sensitive to negative cues (Hall, 1978; Rosenthal et al., 1979). One explanation for this is based on sex difference in brain lateralization. Some research has shown that men have more specialized, lateralized brain functions, whereas women have more symmetrical, integrated brain functions (Anderrsen, Garrison, \& Andersen, 1979).

On the other hand, Alper Joseph (1985) wrote a critical analysis about sex differences in brain asymmetry. According to him there is no proof or even good evidence of sex differences in cognitive or in brain lateralization. In fact, because of the strong environmental pressure on people to act in accordance with the socially accepted norm for their genitally defined sex, these differences are more likely to be due to primarily environmental differences. Because of the lack of theory in the field of brain asymmetry, none of the studies or experiments can be relied upon. According to Alper, differences are commonly found in the field of sex differences in brain asymmetry because there are no theoretical restrictions on the number and types of patterns available for investigation.

A second biological theory that may prove useful in understanding sex differences in lying behavior is the empathizing-systemizing theory (Simon BaronCohen, 2003). This theory specifies that the female brain is predominantly hard-wired 
for empathy, and the male brain is predominantly hard wired for understanding and building systems. Empathizing is the drive to identify another person's emotions and thoughts and treat that person with care and sensitivity. These theories offer an explanation for how women may lie in order to protect other's feelings in this case the partner feelings. Studies have demonstrated, for example that women are more willing and likely to provide emotional support and use comforting messages that clearly distinguish, elaborate upon, and legitimize the feelings of others (Wood, 1994).

In addition to biological approaches to explaining sex differences in lying behavior, there are psychological approaches as well. Two schools of thought have been developed in the psychological literature that may be applied to explain the differences between men and women in lying. The first is an approach in which characteristics of the individual, such as biological sex are observed to comprehend group difference in behavior. The second approach is a social structural approach, in which characteristics of the social context are studied to explain the behavior of individuals in situations (Sagrestano et al. 1998).

From the individual perspective, men and women are biologically or physiologically different. For this reason, they react differently to certain kinds of stimuli, thus resulting in behavioral difference. This difference in physiology has been used to explain behavioral difference between men and women. Researchers as (Gottman \& Levenson, 1988; Levenson, Carstensen, \& Gottman, 1994) have suggested that, as a consequence of their physiological reactivity, men withdraw more from conflict with their spouses than do women, in attempt to stay away from distress 
(as cited in Canary \& Dindia, 1997). This approach explains how men will lie to avoid tension or conflict than will women.

A second individual approach is a socialization approach, having its foundation in the psychodynamic theory. It suggests that men and women grow up in different social worlds, develop different identities, follow different goals and, as a result, behave differently. Miller (1976) stated that women develop a sense of self that is structured around establishing and maintaining relationships, in contrast to men, who develop a sense of self that is structured around separation from others. This approach identifies the fact that women may become motivated more so than men to engage in deceptive behaviors in order to maintain and maximize their relationship.

Social Role Theory is a social structural approach that might lead us to a clearer idea of how men and women are different regarding lying. According to Social Role theory (Eagly, 1987), men and women behave differently in social situations and they assume different roles due to the different expectations that society places upon them. Men and women are differentially separated into social roles, with men occupying higher status roles than women. High status has been found to be associated with expectations of high competence, and men are generally perceived to be more competent than women (Wood \& Karten, 1986). Women are socialized to obey the rules, whereas men are socialized to have power and be in control. As a result, women are seen as more easily influenced because lower status is typically associated with being more easily influenced (Eagly $\&$ Wood, 1982). According to the social role model, men tend to be more in control, have more power and influence in social and private situations than women do, and for that reason men will lie more to establish, 
maintain, maximize power and influence in an intimate relationship or a social interaction.

In summary, these theories show there are differences between males and females and all point out that it is possible to be a sex or gender difference in lying behavior. According to Canary and Dindia (1998), sex refers to the genetic, biological differences between boys and girls, between men and women; gender refers to the psychological and social manifestations of what one believes to be male and/or female, which might-or might not-reflect one's biological sex. Gender is a social, symbolic construction that expresses the meanings a society confers on biological sex. Gender varies across culture, over time within any given society, and in relation to the other gender.

For the most part, differences between women and men involve gender, which is constructed by social ideologies. Biological qualities (the province of sex) are less important than the meaning that society attributes to them and the distinctive roles, opportunities, experiences, and constrains that society assumes are and should be linked with each biological sex (the province of gender).

Not biology, but gender prescribes for females and males account for most differences in priorities, behaviors, attitudes, feelings, and self-concepts of the sexes. So powerfully do socially constructed gender ideologies affect individuals' perceptions and behaviors that they have repeatedly and radically altered ideas of what is and is not masculine and feminine.

People hold sex role stereotypes that prescribe general orientations toward behavior as well they are socialized to live up to stereotypic expectations, even if they 
personally do not adopt them. What women and men are, what they can/should do and look like, what is/is not feminine and masculine are beliefs crafted by social structures and practices that reflect and serve the interests of a particular society at a given time. (Wood \& Dindia, 1998) 
Statement of the Objective and Purpose of the Study.

The purpose of this study is to identify the most common motives for lying by men and women in intimate relationships and possible sex or gender differences in lying behavior.

Although there is quite a bit of research that has examined motives for lying rarely has such research targeted intimate relationships and sex or gender differences specifically. Of the motivation classification schemes developed, Turner's classification of motives for lying will be used for: 1) examining which motives are present in intimate relationships, and 2) determining whether there are sex or gender differences in motives in the these relationships.

Research doesn't treat motives for lying in intimate relationships in a comprehensive way. Some studies examine motives for lying in all interpersonal relationships, other deal with lying in intimate relationships but research undertaken to date has not concentrated on sex or gender differences in motives for lying in romantic relationships. This research tested and refined Turner's motivations for lying concentrating only on intimate relationships and sex differences. Turner identified five motives for lying. Four of these motives were examined in this study to determine whether they are characteristics of motivations in intimate relationships, and possibly identify how men and women differ in their motivations for lying. The four motivations are: (i) to save face (either their own, the partner's ); (ii) to maintain, maximize or terminate an intimate relationship; (iii) to avoid tension and conflict, (iv) to establish, maintain or maximize power or influence over another. I excluded the motive "to establish, maintain or terminate a social interaction" because it is not 
related to intimate relationships and this study deals only with people involved in an intimate relationship.

To understand the role of lying in close relationships, it is important to understand the nature and motivations of lies that are told in relationships. Over the past several decades a handful of studies on motives of lying in interpersonal relationships have been published (Camden, Motley \& Wilson, 1984; Hample, 1980; Linskold \& Walters, 1983; Lipard, 1988; Turner et al, 1975). These studies have greatly increased our knowledge of the nature of motivation people have to lie. People tell lies to try to make themselves look better, to protect themselves from embarrassment or disapproval, to avoid tension or conflict, to control or terminate a relationship, and to try to gain the affection of other people.

Past research has shown that people have different motives for lying also prior research and theories indicates that there may be a sex or gender difference in lying behavior. On the basis of these arguments, I hypothesize that women and men have different motives for lying in intimate/romantic relationships.

H1: Men will score higher on lying for protecting their own face than women.

H2: Women will score higher on lying for protecting other's face (the partner's) than men.

H3: Men will score higher on lying in order to avoid tension or conflict than women will.

H4: Women will score higher on lying for purposes of establishing or maintaining a relationship than men will. 
H5: Men will score higher on lying for the purpose of establishing, maintaining and maximize power and influence in intimate relationships than women will.

Prior hypotheses stated that there is a possibility to be sex differences in lying behavior but also there is the possibility to have gender differences, the way people internalize notion of masculinity and femininity, so I propose:

H6: Femininity scores will be negatively associated with lying for protecting own face.

H7: Femininity scores will be positively associated with lying for protecting other's face (the partner's).

H8: Femininity scores will be negatively associated with lying in order to avoid tension or conflict.

H9: Femininity scores will be positively associated with lying to maintain relationship.

H10: Femininity scores will be negatively associated with lying to maintain power in relationship.

H11: Masculinity scores will be positively associated with lying for protecting own face.

H12: Masculinity scores will be negatively associated with lying for protecting other's face (the partner's).

H13: Masculinity scores will be positively associated with lying in order to avoid tension or conflict.

H14: Masculinity scores will be negatively associated with to maintain relationship. 
H15: Masculinity scores will be positively associated with lying to maintain power in relationship. 


\section{Method and Design/Procedure}

Sample

A total of 250 URI students, (98 males and 158 females), aged between 19-25 years old, were asked to fill out an anonymous questionnaire about deception in romantic relationships. All participants were currently involved in a romantic relationship at the time of the study or had been involved in such a relationship in the recent past. Participants were asked to recall a prior serious deceptive experience with a relational partner.

A questionnaire tapping deception motives had been administrated to students in sections of COM. 100 and COM 382. COM 100 is the department of Communication Studies introductory course and is typically taken by students in their freshman or sophomore year. COM 382 is typically taken by students in their junior or senior year. I described the study to students and I answered questions without reveling the exact purpose of the study. I also made sure the students did not put their name on the questionnaires because answers were anonymous. Student participation was voluntary. Students received extra credit for participation.

\section{Materials and Procedures}

The first page of the questionnaire defined deception as follows:

Deception is any verbal message that one partner sends with the intent of leading the other partner to a belief or a conclusion that the sender considers to be less than absolutely true or less than totally complete. A deceptive message may involve providing information that is either untrue or has been exaggerated or distorted in some manner, or may involve deliberately omitting information such that a partner is led to an incorrect conclusion or belief.

Immediately following this definition, participants were instructed to base their responses on their current romantic relationship or, if they were not romantically 
involved at the time of the study, on a past relationship. Participants also indicated their age, sex and ethnicity as well as the length of time spent in the relationship on which they base their responses to items in the questionnaire. Also participants were asked to specify the status (present or past) of the relationship that served as their target relationship.

The first portion of the questionnaire will determine what motives they acted upon when engaged in deception in romantic relationships. The questionnaire contains 20 items each with a five-point $(1=$ completely disagree, $2=$ disagree, $3=$ not sure, $4=$ agree, $5=$ completely agree) Likert response scale. Participants were instructed to answer these questions while keeping in mind that there are no right or wrong answers.

There is no validated scale to assess motives for lying in intimate relationships; therefore, I composed a 20 item questionnaire, specifically for the purpose of this study. The items on this questionnaire are based loosely on typologies used by Turner et al. (1975), and Kaplar \& Gordon (2004) to examine lying motives in relationships other than romantically based ones. Some of the items are an adaptation of Turner's motives and I made them appropriate for this study. Participants indicate their level of agreement or disagreement with the 20 statements using a Likert Scale ( $5=$ completely agree; $1=$ completely disagree). The questionnaire included items such as: I lied to avoid hurting my partner; I lied to avoid a fight; I lied to avoid negative consequences. The 20 items tap four major motives; (i) to save face (either their own, the partner's ); (ii) to maintain, maximize or terminate an intimate relationship; (iii) to avoid tension and conflict, (iv) to establish, maintain or maximize power or influence 
over another. There were four items per motive. For better results the first motive (to save face, either their own, or their partner's) was treated as 2 motives (to save own face; to save partner's face) each having 4 items.

A pretest was administrated to volunteers. The purpose of the pretest was to determine whether participants have any problems in filling out the measure.

In the second part of the questionnaire students were asked to complete a Personal Attributes Questionnaire (Spence, Helmreich, \& Stapp 1974). This instrument is composed of twenty-four bipolar items describing personal characteristics, on each of which respondents are to rate themselves on a five-point scale. The questionnaire is divided into three eight-item scales, labeled Masculinity (M), Femininity (F), and Masculinity-Femininity (M-F). Each item is scored from 1 to 5, a high score on items assigned to the $\mathrm{M}$ and $\mathrm{M}-\mathrm{F}$ indicating an extreme masculine response and a high score on $\mathrm{F}$ scale items indicating an extreme feminine response. Masculine items are defined as characteristics socially desirable in both sexes but believe to occur to a greater degree in males. Feminine items are similarly defined as socially desirable characteristics said to occur to a greater degree in women. M-F items are defined as opposites sides, suggesting that is socially desirable for one sex is not socially desirable for the other.

Statistical Analyses

In testing the hypotheses one thorough five, MANOVA procedures were used. For the hypotheses subjects fell into two mutually exclusive categories: males and females. Males' and females' motives for lying were compared. In the classic MANOVA sense, gender may be said to be the independent variable and the five 
different motives the dependent variable. Hypotheses six through fifteen were tested by examining the Pearson Product Moment Correlation Coefficient. Participants were identified on the base gender, the extent to which they perceived themselves as masculine or feminine. 


\section{Results}

The independent variable was assessed in two ways. First; participants were identified as males or females (what I will refer to as sex) and differences in the means on each of the lying motives were examined, and second as sex roles (indicated by the degree of femininity and masculinity as measured by the Personal Attributes Questionnaire (Spence, Helmreich, \& Stapp, 1974). I used sex to refer to the biological sex of the individual - whether a person is born physically female or male. Gender refers to the psychological and social manifestations of what one believes to be male and/or female, which might - or might not- reflect one's biological sex. Gender means "being masculine" or " being feminine", gender is the internalization of masculinity and femininity.

With regard to motives for lying in relationships, a one-way MANOVA did not reveal any significant differences between females and males. $F(244)=.758$, Wilks' Lambda $=.985, p>.05$. Although the overall test didn't show significant differences, two of the individual tests approached significance: men lied more $(\mathrm{M}=2.99, \mathrm{SD}=$ 1.06) to avoid conflict than women $(\mathrm{M}=2.79, \mathrm{SD}=1.13) ; \mathrm{F}(1,248)=1.92, p>.05 . p$ $=.16$.

Men also scored higher $(\mathrm{M}=2.02, \mathrm{SD}=.95)$ on lying for the purpose of establishing, maintaining and maximize power and influence in intimate relationships than women $(\mathrm{M}=1.89, \mathrm{SD}=.91 ; \mathrm{F}(1,248)=1.15, p>.05, p=.28$.

On the basis of the overall test, hypotheses 1-5 did not receive support; there appear to be no statistically significant differences between males and females in their motivation for lying in relationships, although two of unvariate tests approached 
statistical significance. These were hypothesis three, that men will score higher on lying in order to avoid tension to avoid conflict that women will, and hypothesis five, that men will score higher on lying for the purpose of establishing, maintaining and maximizing power and influence in intimate relationships than women will.

Hypotheses 6-15 were tested with the Pearson Product Moment Correlation Coefficient. Participants were identified on the basis of gender, the extent to which they perceived themselves as masculine or feminine.

Hypotheses 6-10 were concerned with motives for lying in relationships and femininity. Out of the five hypotheses, three received support, one was contradicted and results for the other were not statistically significant. Hypothesis six, that femininity scores will be negatively associated with lying for protecting own face was supported; $(r=-.143, p<.05)$. Hypothesis seven, that femininity scores will be positively associated with lying for protecting other's face (the partner's) was not supported; $(r=-.059, p>.05)$. Results for hypothesis eight, that femininity scores will be negatively associated with lying to avoid tension and conflict in relationships approached significance; $(r=-.086, p>.05), p=.089$. Hypothesis nine, that femininity scores will be positively associated with lying to establish and maintaining a relationship, was contradicted by the findings; $(r=-.124, p<.05)$. The higher a person's femininity score, the less likely they were to lie for the purpose of establishing and maintaining a relationship. Hypothesis ten, that femininity scores will be negatively associated with lying in order to establish, maintain and maximize power and influence in relationships received support $(r=-.201, p<.01)$. 
Hypotheses 11-15 were concerned with motives for lying in relationships and masculinity. Out of the five hypotheses, one was supported and the results for tests of the remaining for did not yield statistically significant result significance. Hypothesis fifteen, that masculinity scores will be positively associates with lying to maintain power in the relationships, was supported $(r=.122, p<.05)$. 


\section{Discussion}

Previous research has indicated that deception among romantic partners is more likely to be motivated by a concern for the relationship and for a partner when compared with the motives underlying the use of deception in other types of relationships (see Metts, 1989). These comparative studies show that the frequency, motives and effects of deception varies across relationship types (strangers, acquaintances, friends, romantic partners) but they fail to provide sufficient information regarding partners' motives for lying in a romantic relationship and possible sex or gender differences.

In this study I identified and examined the most common motives for lying in intimate relationships and the possible sex and gender differences in this lying behavior. Prior research indicates that there may be sex or gender differences in lying behavior but these studies did not concentrate solely on motivation for lying.

Although there is quite a bit of research that has examined motives for lying, rarely has such research targeted intimate relationships and sex or gender difference, specifically. Of the motivation classification schemes developed, Turner's classification of motives for lying was used in the present study for; 1) examining which motives are present in intimate relationships, and 2) determining whether there are sex and gender differences in motives in the these relationships. Turner identified five motives for lying. Four of these motives were examined in this study to determine whether they are characteristics of motivations in intimate relationships, and possibly identify how men and women differ in their motivations for lying. For better results the first motive (to protect your own face; to protect partner's face) was treated as two 
separate motives. The five motivations are: (i) to protect your own face; (ii) to protect the partner's face; (iii) to maintain, maximize or terminate an intimate relationship; (iv) to avoid tension and conflict, (v) to establish, maintain or maximize power or influence over another.

This study provided three pieces of evidence for the existence of motive for lying;

1. Prima Facie

2. Based on prior research on deception.

3. There where no questions asked of their validity by participants on the pretest and on the actual study.

In hypotheses 1 through 5, I examined whether biological sex (male and female) was linked to lying motivation, while hypothesis $6-15$, I examined whether gender (masculinity and femininity) was associated with lying motivation.

The results of the present study showed that all of the motives examined are present in intimate relationships. Men and women lie to protect themselves, to protect their partner, to maintain an intimate relationship, to avoid conflict and to have power over their relationships.

However, when examining the relationship between biological sex and motivation for lying results are not generally consistent with the hypotheses. The overall test of differences appears to show that there are no statistically significant differences between males and females in their motivation for lying in intimate relationships. Two of the univariate tests, however, showed marginally significant, but small, differences. It appears then, that sex had a limited effect on motivation for 
lying, and where one might sat that differences do exist, those differences are very small. The results of tests of these hypotheses appear to be more consistent with a sex similarity than a sex differences position.

The issue of how biological sex and social gender interact - how much our "masculine" or "feminine" behavior is unavoidably determined by our physical sexunderlines most of the controversies in the science of sex and gender. (Caplan \& Caplan, 1999).

The foundation for these hypotheses was theories of sex differences and past research. One of these theories which is biologically based is the theory of social sensitivity (Hall, 1978). According to this theory, women are genetically predisposed to greater social sensitivity. Several studies have shown that females are particularly sensitive to negative cues (Hall, 1978; Rosenthal et al., 1979). One explanation for this is based on a difference in brain lateralization.

At first glance the results of the present investigation give one cause to wonder about the validity of biological sex differences theories, at least as they are applied to lying motives. For example, the theory of social sensitivity (Hall, 1978) is based on brain lateralization. We have to take in consideration that the theory was developed 30 years ago and it may not be reliable. According to Wood and Dindia (as cited in Canary \& Dindia, 1998) any sex differences that might exist are minor in view of the overwhelming genetic-biological similarities between women and men. Further, some differences generally attributed to biology, such as brain lateralization, may reflect environmental influences. 
Neuroscientist Bleir (1986) stated that reported sex differences in brains predominantly reflect environmental factors - a matter of gender, not sex. Alper Joseph (1985) also stated that there is no proof or even good evidence of sex differences in cognitive or in brain lateralization. In fact, because of the strong environmental pressure on people to act in accordance with the socially accepted norm for their genitally defined sex, these differences are more likely to be due to primarily environmental differences. Because of the relative lack of theory in the field of brain asymmetry the studies or experiments that have found differences between men and women can be questioned in terms of underlying root cause (biological sex) of those differences. Biological sex differences may create behavioral tendencies -, but they may not determine individuals' behavior.

The results of tests of the first five hypotheses seem to demonstrate that there is no sex difference in motivations for lying in intimate relationships, and hence seems to negate a biologically-based theory of lying motivation.

Hypotheses 6 - 15 were grouped in two categories and, rather than focusing on biological sex, examined whether the extent to which individuals have internalized notion of masculinity and femininity is associated with lying motives in intimate relationships. This internalization, consistent with many previous investigations, I have termed "gender".

Results of test of these hypothesis showed that there do appear to be associations between gender and lying behavior. Hypotheses 6-10 were focused on the relationship between motives for lying in intimate relationships and the extent to which participant have internalized femininity. Although evolution has produced 
biological tendencies that represent slightly different predisposition for men and women, nobody can exclude any human from any role to which they might aspire. It is true that, biology may underlie some predispositions but we are not completely inevitable by-products of our biology (Andersen 1998). Individuals can choose to be more or less feminine or masculine.

Out of the five hypotheses concerned with motives for lying in relationships and the extent to which participant have internalized femininity, three received support, one was contradicted and results for the other were not statistically significant. The results of three of the hypotheses are in accordance with the existing theory and the hypotheses themselves. Hypothesis six, that femininity scores will be negatively associated with lying for protecting own face was supported and tends to support the view that the more feminine an individual is the less she/he will lie to protect themselves. Hypothesis seven, that femininity scores will be positively associated with lying for protecting other's face (the partner's) was not supported. The motive "lying to protect other's face" was one of the most used motives by participants. However, no sex or gender differences were found according to the results. Results for hypothesis eight, that femininity scores will be negatively associated with lying to avoid tension and conflict in relationships approached significance. Hypothesis nine, that femininity scores will be positively associated with lying to establish and maintaining a relationship, was contradicted by the findings. It is possible that the theory and past research is old and may not be applicable to today's population. The concept of femininity changed during the time. Femininity is still associated with soft and carrying, but not with submissive and rather independent. 
Feminine individuals do not rely as much on relationships for emotional and financial support and they do not necessarily develop a sense of self that is structured around establishing and maintaining a relationship, like they used to 30 years ago. Feminine individuals are more independent and having a relationship or a family might not be the first priority in young people's mind. Hypothesis ten, that femininity scores will be negatively associated with lying in order to establish, maintain and maximize power and influence in relationships received support . As predicted and verified by the results, more feminine individuals tend not to lie to avoid tension and to maintain power in the relationship.

Hypothesis 11-15 were focused on the relationship between motives for lying in intimate relationships and the extent to which participants have internalized masculinity. One of these hypotheses was supported: masculinity scores were positively associated with lying to maintain power in the relationships. The hypothesis was based on Social Role Theory, which is a social structural approach. According to Social Role theory (Eagly, 1987), men and women behave differently in social situations and they assume different roles due to the different expectations that society places upon them. Men and women are differentially separated into social roles, with men occupying higher status roles than women. High status has been found to be associated with expectations of high competence, and men are generally perceived to be more competent than women (Wood \& Karten, 1986). Women are socialized to obey the rules, whereas men are socialized to have power and be in control. As a result, women are seen as more easily influenced because lower status is typically associated with being more easily influenced (Eagly \& Wood, 1982). According to the 
social role model, men tend to be more in control, have more power and influence in social and private situations than women do, and for that reason men will lie more to establish, maintain, maximize power and influence in an intimate relationship or a social interaction. To the extent that men and women have differentially internalized these roles, we should see sex differences. To the extent these roles have not been differentially internalized by men and women, we should not see sex differences, but rather differences in the extent to which roles have been internalized; in short - gender difference.

To the extent that we hold stereotypes beliefs about men and women, these beliefs can lead us to differential expectations about how people will behave based on their sex. Men are described as leaders - as dominant, aggressive, independent, and competitive. Women are described as emotional, subjective, and aware of feeling of others. These stereotypes have remained relatively stable over the past 20 years. People are expected to behave in a manner consistent with their roles. Thus, gender stereotypes have both descriptive and a prescriptive component. They indicate what group members are like, but also what group members should be like (Eagly \& Wood 1982).

Cultures provide rich and well-differentiated sets of concepts and terms to label and characterize boys and girls, men and women, to separate between female and male roles, rights and responsibilities. In all known cultures, females and males meet with distinct sets of gender-related beliefs and expectations exerting powerful, and often subtle, influence on their thoughts, feelings, and behaviors (Eckes \& Trautner, 2000) 
In today's society people do not necessarily behave in a manner consistent with their roles. As the results of this study demonstrated masculine individuals were positively associated with lying for establishing, maintain power and influence over a relationship.

The world has changed, males and females have changed and perhaps the strength of socialization and internalization of these stereotypes on the basis of sex are diminishing. Such a change would indicate that we will see few biologically-based sex differences between males and females. Further, any such differences that are observed will likely be small in magnitude.

Take, for example, the participants of this study; they tended to be young students. Their world is different that it used to be 30,20 or even 10 years ago when the sex differences theories and research in lying behavior were developed. They have different ways of communicating with each other, they socialize differently. Men and women are not the same as they used to be. Young men and women may be much more even, much more equal, and less sex specific in their social interaction. Today, young people are likely to have as many male friends as females.

The differentiation in behaviors, the social barrier, the distinct social differences were much clearer in the past, than they are now. Young females and males behave, talk and think very similarly. Young people these days are much more accepting and aware of sex and gender. They are less likely to feel like they need to conform to sex role norms. Perhaps there were those barriers that society imposed and the perception of gender, and how you suppose to behave, think and talk according to your biological sex that made behavior different for men and women. Culturally, the 
rate of change is extremely rapid. Thus, our biological traits evolved under environmental circumstances very different than the present. Thus, women who may have evolved superior social skills as caregivers don't need to use those skills as caregivers in today's cultural setting but may use those social skills creatively as managers, teachers, or doctors. Men no longer need their superior spatial skills for hunting but may find them useful in navigation tasks, professional sports, or engineering. Biology is not destiny (Andersen, 1998).

Regardless of the status of scientific evidence on the convergence of the sexes, perceivers believe that men and women are becoming more similar. These beliefs have been demonstrated by Diekman and Eagly ( in press), who showed that people believe that women and men have converged in their personality, cognitive, and physical characteristics during the past 50 years and will continue to converge during the next 50 years (Eagly, Wood \& Diekman, 2000).

Past social ideologies prescribed that men and women be allowed some and not the other experiences (football and cheerleading; hunting and ballet; president, and first lady). These differences are profound asymmetric in the social, economic and political power. These social ideologies may have trouble fitting in with today's society. Males and females can sometimes enjoy the same experiences. Masculinity, it seems is diminishing in its link to male as is femininity to women (Canary \& Dindia, 1998).

Eagly (1987) stated that many sex differences can be attributed to the differential distribution of men and women into different social roles and that when men and women occupy the same roles, they will behave similarly. In today's society 
women are doing better in the work place, they are reaching higher that ever before; the glass ceilings are not as prevalent. Women have quietly taken over in business, industry and the profession; they are distinguishing themselves in civil and public service; they are scientists and spacepersons, they are making their mark on the media not as pretty-face performers but as professional power-houses (Miles, 1986). The expectations of social behavior, social success, professional success, financial success are becoming homogeneous.

In so many ways, in the United States especially, socially and culturally, those defined differences that we talked about, are not nearly as clear as they used to be, and that may be what was driving the homogeneity of male and female responses to the questionnaires.

As Caplan and Caplan (1999) stated it is virtually impossible to know what inevitable sex differences there might be, since so much of the research is deeply flawed and since males and females have nowhere been treated identically from birth. It is difficult, if not impossible, to be aware of all the biases and unquestioned assumptions; and those who research sex differences will bring those factors into the research. We are all products of our time and culture.

When we study sex differences, we can get so absorbed in thinking about the details of the study that we lose sight of the larger perspective. Part of the larger perspective that we need to keep in mind is that, since each scientist will be able to explore only a limited number of research questions, there must be a reason that some choose to spend their lives trying to find sex and gender differences. 
Canary and Dindia (1998) state that sex difference findings have been mixed and inconclusive in studies of deception. Moreover, no theoretical explanation of deceptive communication has emphasized sex as an important feature. The results of the present study corroborate Canary and Dindia's claim that biological sex by itself is not an important factor in lying motivation.

By examining these hypotheses I am able to conclude that all the motives discussed in this study were present in intimate relationships, but motives are not different for males and females; however, motives may be different for individuals who have differentially internalized notions of masculinity and femininity regardless of biological sex. That is that there is no sex difference in men's and women's motivation to lie to their partners but rather gender differences. 


\section{Limitations and Future Research}

This study represents an ambitious attempt to explore motives in intimate relationships and sex or gender differences. For this reason I have to comment on some limitations and provide some support for future research.

In this research, I asked students to complete a questionnaire about lying in relationships. They were asked to recall a previous serious lie that they told to their partners, and complete the questionnaire. It is important, then, to address the question of whether they were really thinking about one single lie. It is possible that some of the responses were based on more than one specific lie. The questionnaire was designed to cover the five motives of lying in relationships but for one specific lie.

The instruction to think about "a serious lie" might have biased the results. Participants recalled lies having to do with feelings, behaviors and past relationships. The seriousness of the lie depends of the participants' personal experiences and the emotional involvement in that particular relationship. Participants' responses may have reflected, at least in part, their belief that they were expected to furnish a particular type of answer. This study relies on self-report measures and the findings might be colored by socially desirable responding. Lies told in a long-term relationship are different than lies told in a new relationship. In a long relationship individuals tend to be more involved and have much more to lose. Individuals involved in a romantic relationship are also interested in the relational outcome. To be trapped in a lie not only ruins the immediate objective of the deceit, it also affects the relationship itself. Being lied to by a stranger is often economically or professionally punishing, but being lied to by a romantic partner can be personally and relationally 
devastating. The relationship between intimate partners is usually severely altered if lying is detected. Of course the outcome depends on the significance of the lie and the importance that it has for a particular individual and relationship (Miller, Mongeau, \& Sleight, 1986).

Another limitation centers on the participants' population. The participants of the study were students, mostly coming from the COM 100. COM 100 is an introductory communication course; typically taken by freshmen or sophomores. It is essential, then to address a few questions, such as whether they took this questionnaire seriously or they completed for extra credit taking advantage that the questionnaires were anonymous.

Most of the participants were involved in relatively short-term relationships. It is possible that in other population, perhaps adults whom are married or having longterm relationships, the motives for lying will apply differently.

The questionnaires were completed by American students. Even if some of the participants have different backgrounds, the results of this study cannot be applied to members of different cultures. Understanding the systematic differences in how people perceive and interpret lies may help clear some of the misunderstandings that occur in incidents involving lying.

In the second part of the questionnaire participants completed the Personal Attribute Questionnaire (Spence, Helmreich, \& Stapp,1974). According to this a typical man makes decision easily, doesn't not give up easily, and it is not easily influenced, not excitable in major crises, competitive, outspoken, interested in sex, outgoing, intellectual, self-confident, and the like. The typical woman likes children 
and is relational, emotional, considerate, tactful, gentle, helpful to others, aware of other's feelings, warm, and so forth. These items reflect traditional sex role stereotypes held during the early 1970s. It is important than to address the question whether the items are not due for an overhaul. The items of the questionnaire tapped into what feminine and masculine used to be 34 years ago and perhaps it needs a reconsideration of what is feminine and masculine in today's society.

In this study I used questionnaire to test motives for lying. It is true that a researcher using questionnaire methods may obtain different results that had they used content analysis (and vice versa).For example, in their study of deception, Kaplar and $\&$ Gordon (2004) obtained different results when using the questionnaires versus the content analysis.

In conclusion although the current investigation provides insight with regard to a previously unresearched area, certain issues deserve further attention. Future researchers are encouraged to explore motives in intimate relationship and sex or gender differences with different age group participants and using different methods. Only through continued exploration we will understand if there is indeed a difference between men and women and lying motivation. I believe that such research is necessary for a richer and fuller understanding of the process of motivation for lying. 
Read the definition below.

\section{Appendix}

Deception is any verbal message that one partner sends with the intent of leading the other partner to a belief or a conclusion that the sender considers to be less than absolutely true or less than totally complete. A deceptive message may involve providing information that is either untrue or has been exaggerated or distorted in some manner, or may involve deliberately omitting information such that partner is led to an incorrect conclusion or belief.

Please think about a time when you have seriously lied or deceived to your partner. Try to answer the following statements as honestly as you can. Please base your responses on your current romantic relationship or if you are not romantically involved at this time, on a recent past romantic relationship. Only people who've had or are having romantic relationships are eligible to participate in this study.

\section{Part A}

Please indicate your:

GENDER : MALE FEMALE

ETHNICITY :

\section{AGE}

1. How long had you been in this relationship. years months weeks

2. Is this a past or present relationship?

past present 
3. If past, how long ago was it terminated.

years

months

weeks

\section{Part B}

For each of the statements below think about the last time you told a serious lie to your partner.

Please indicate the extent of your agreement or disagreement by circling the number that applies.

The response scale is as follow:

$1=$ Completely disagree

$2=$ Disagree

$3=\quad$ Not Sure

$4=$ Agree

$5=$ Completely agree

\begin{tabular}{|c|c|c|c|c|c|c|}
\hline 1. & I lied to my partner to protect myself & 1 & 2 & 3 & & 5 \\
\hline 2. & I lied to my partner because I didn't want him/her to lose trust in me & & & & & \\
\hline 3. & I lied because I didn't want to embarrass myself in front of her/him & 1 & 2 & 3 & 4 & 5 \\
\hline 4. & I lied because was in my own best interest & 1 & 2 & 3 & 4 & 5 \\
\hline 5. & I lied because I didn't want to hurt her/his feelings & 1 & 2 & 3 & 4 & 5 \\
\hline 6. & I lied because it was in my partners' best interest & 1 & 2 & 3 & 4 & 5 \\
\hline 7. & I lied to spare my partner unnecessary pain or suffering & 1 & 2 & 3 & 4 & 5 \\
\hline 8. & I lied because I wanted my partner to feel good & 1 & 2 & 3 & 4 & 5 \\
\hline 9. & I lied because was in the best interest of our relationship & 1 & 2 & 3 & 4 & 5 \\
\hline 10. & I lied because relationally I didn't feel it was the right time for the truth & 1 & 2 & & 4 & 5 \\
\hline
\end{tabular}




\begin{tabular}{|ll|l|l|l|l|l|}
\hline 11. I lied because I didn't want to lose my girlfriend/boyfriend & 1 & 2 & 3 & 4 & 5 \\
\hline 12. & I lied because I wanted to finish the relationship & 1 & 2 & 3 & 4 & 5 \\
\hline 13. & I lied because it made me feel in control & 1 & 2 & 3 & 4 & 5 \\
\hline 14. & I lied to my partner so I could get what I wanted & 1 & 2 & 3 & 4 & 5 \\
\hline 15. & I lied because I knew he/she would believe whatever I say & 1 & 2 & 3 & 4 & 5 \\
\hline $16 . \quad$ & I lied because I don't want him/her to have power over me & 1 & 2 & 3 & 4 & 5 \\
\hline $17 . \quad$ & I lied to avoid a bad scene & 1 & 2 & 3 & 4 & 5 \\
\hline 18. & $\begin{array}{l}\text { I lied because if I had given an honest answer he/she would have } \\
\text { started another argument }\end{array}$ & 1 & 2 & 3 & 4 & 5 \\
\hline $19 . \quad$ & $\begin{array}{l}\text { I lied so my partner would stop asking questions and leave me } \\
\text { alone }\end{array}$ & 1 & 2 & 3 & 4 & 5 \\
\hline 20. & I lied because I hate conflict between us & 1 & 2 & 3 & 4 & 5 \\
\hline
\end{tabular}

\section{Part C}

Instructions:

The items below inquire about what kind of person you think you are. Each item consists of a PAIR of characteristics, with the letters A-E in between. For example,

Not at all artistic
A......B
B.................E
Very artistic

Each pair describes contradictory characteristics - that is, you cannot be both at the same time, such as very artistic and not at all artistic.

The letters form a scale between the two extremes. You are to choose a letter which describes where YOU fall on the scale. For example, if you think that you have no 
artistic ability, you would choose A. If you think that you are pretty good, you might choose D. If you are only medium, you might choose $\mathrm{C}$, and so forth.

\begin{tabular}{|c|c|c|c|}
\hline 1. & Not at all aggressive & $\mathrm{A} \ldots \ldots \mathrm{B} \ldots \ldots \mathrm{C} \ldots \ldots \mathrm{D} \ldots \ldots \mathrm{E}$ & Very aggressive* \\
\hline 2. & Not at all independent & A ….................. & Very independent* \\
\hline 3. & Not at all emotional & $\mathrm{A} \ldots \ldots \mathrm{B} \ldots \ldots \mathrm{C} \ldots \ldots \mathrm{D} \ldots \ldots \mathrm{E}$ & Very emotional* \\
\hline 4. & Very submissive & 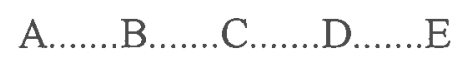 & Very dominant* \\
\hline 5. & $\begin{array}{l}\text { Not at all excitable in a } \\
\text { major crisis* }\end{array}$ & $\mathrm{A} \ldots \ldots . \mathrm{B} \ldots \ldots . \mathrm{C} \ldots \ldots \ldots \ldots$ & $\begin{array}{l}\text { Very excitable in a } \\
\text { major crisis }\end{array}$ \\
\hline 6. & Very passive & A ....................... & Very active* \\
\hline 7. & $\begin{array}{l}\text { Not at all able to devote self } \\
\text { completely to others }\end{array}$ & $\mathrm{A} \ldots \ldots \mathrm{B} \ldots \ldots \mathrm{C} \ldots \ldots \ldots \ldots$ & $\begin{array}{l}\text { Able to devote self } \\
\text { completely to others* }\end{array}$ \\
\hline 8. & Very rough & A .........................E & Very gentle* \\
\hline 9. & Not at all helpful to others & $\mathrm{A} \ldots \ldots . \mathrm{B} \ldots \ldots . \mathrm{C} \ldots \ldots . \mathrm{D} \ldots \ldots \mathrm{E}$ & Very helpful to others* \\
\hline 10. & Not at all competitive & 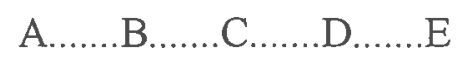 & Very competitive* \\
\hline 11. & Very home oriented & 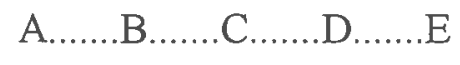 & Very worldly* \\
\hline 12. & Not at all kind & A …....................E & Very kind* \\
\hline 13. & $\begin{array}{l}\text { Indifferent to others } \\
\text { approval* }\end{array}$ & A …...................E & $\begin{array}{l}\text { Highly needful of } \\
\text { others' approval }\end{array}$ \\
\hline 14. & Feelings not easily hurt* & A $\ldots \ldots$ B................. & Feelings easily hurt \\
\hline 15. & $\begin{array}{l}\text { Not at all aware of feelings } \\
\text { of others }\end{array}$ & A ........................ & $\begin{array}{l}\text { Very aware of feelings } \\
\text { of others* }\end{array}$ \\
\hline 16. & Can make decisions easily* & A …...................E & $\begin{array}{l}\text { Has difficulty making } \\
\text { decisions }\end{array}$ \\
\hline 17. & Gives up very easily & A …............... D .....E & Never gives up easily* \\
\hline 18. & Never cries* & $\mathrm{A} \ldots \ldots \mathrm{B} \ldots \ldots \mathrm{C} \ldots \ldots \mathrm{D} \ldots \ldots \mathrm{E}$ & Cries very easily \\
\hline
\end{tabular}




\begin{tabular}{|c|c|c|c|}
\hline 19. & Not at all self-confident & 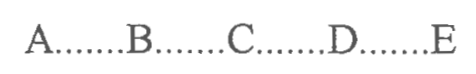 & Very self-confident* \\
\hline 20. & Feels very inferior & $\mathrm{A} \ldots \ldots \mathrm{B} \ldots \ldots \mathrm{C} \ldots \ldots \mathrm{D} \ldots \ldots \mathrm{E}$ & Feels very superior* \\
\hline 21. & $\begin{array}{l}\text { Not at all understanding of } \\
\text { others }\end{array}$ & $\mathrm{A} \ldots \ldots \mathrm{B} \ldots \ldots \mathrm{C} \ldots \ldots \mathrm{D} \ldots \ldots$ & $\begin{array}{l}\text { Very understanding of } \\
\text { others* }\end{array}$ \\
\hline 22. & $\begin{array}{l}\text { Very cold in relations with } \\
\text { others }\end{array}$ & A .......................... E & $\begin{array}{l}\text { Very warm in relations } \\
\text { with others* }\end{array}$ \\
\hline 23. & $\begin{array}{l}\text { Very little need for } \\
\text { security* }\end{array}$ & 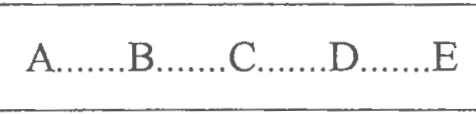 & $\begin{array}{l}\text { Very strong need for } \\
\text { security }\end{array}$ \\
\hline 24. & $\begin{array}{l}\text { Goes to pieces under } \\
\text { pressure }\end{array}$ & $\mathrm{A} \ldots \ldots \mathrm{B} \ldots \ldots \mathrm{C} \ldots \ldots \mathrm{D} \ldots \ldots . \mathrm{E}$ & $\begin{array}{l}\text { Stands up well under } \\
\text { pressure* }\end{array}$ \\
\hline 25. & Honest & $\mathrm{A} \ldots \ldots \mathrm{B} \ldots \ldots \mathrm{C} \ldots \ldots \mathrm{D} \ldots \mathrm{E}$ & Dishonest \\
\hline
\end{tabular}

If your answers were based on a past relationship, did the lie terminate the relationship?

yes no

Your partner sex is male female.

Was the lie you've told primarily about a:

(a) feeling

(b) behavior

(c) past relationship.

Please circle only one. 


\section{Bibliography}

Alper, J. S. (1985). Sex difference in brain asymmetry: A critical analysis. Feminist Studies, 11, 7-37.

Andersen, P.A (1998). Researching sex differences within sex similarities: The evolutionary consequences of reproductive differences. In D.J. Canary \& K.Dindia (Ed), Sex differences and similarities in communication (pp. 83-100), New Jersey: Lawrence Erlbaum.

Andersen, P. A., Garrison, J. P., \& Andersen, J. F. (1979). Implication of a neurophysiological approach for the study of nonverbal communication. Human Communication Research, 6, 74-89.

Baxter, L. A. (1990). Dialectical contraction in relational development. Journal of Social and Personal Relationships, 7, 69-88.

Bok, S. (1978). Lying: Moral choice in public and private life. New York: Pantheon Books.

Boon, S. D., \& McLeod, B. A. (2001). Deception in romantic relationships. Journal of Social and Personal Relationships, 18, 463-476.

Buller, D. B., \& Burgoon, J. K. (1996). Interpersonal deception theory. Communication Theory, 3, 2003-242.

Burgoon, J. K., Buller, D, B., \& Woodall, G. (1996). Nonverbal communication: The unspoken dialog $\left(2^{\text {nd }}\right.$ ed.). New York: McGraw-Hill.

Canary, D. J., \& Dindia, K. (1998). Sex differences and similarities in communication. New Jersey: Lawrence Erlbaum.

Canary, D. J., \& Emmers-Sommer, T. M. (1997). Sex and gender differences in personal relationships. NY: The Guilford Press.

Camden, C., Motley, M., \& Wilson, A. (1984). White lies in interpersonal communication: A taxonomy and preliminary investigation of social motivations. The Western Journal of Speech Communication, 48, 309-325.

Cody, M. J., \& O' Hair, H. D. (1983). Nonverbal communication and deception: Differences in deception cues due to gender and communicator dominance. Communication Monographs, 50, 175-192.

Cohen, S. B. (2003). The essential difference: The truth about the male and female brain. New York: Perseus Book Group.

Cole, T. (2001). Lying to the one you love: The use of deception in romantic relationships. Journal of Social and Personal relationships, 18, 107-129. 
Cole, T. (2005). Deception confidence in romantic relationships: Confidently lying to the one you love. In S. P. Shohov (Ed.), Advances in Psychology Research (pp. 127139).Hauppauge, NY: Nova Science Publishers.

Donaghy, W. C., Grandpre, J. R., \& Davies, L. (1994). Validating deception detection stimuli: Grouped data vs. subject-to-subject approaches. Paper presented to the annual meeting of the Western Speech Communication Association, San Jose, CA.

DePaulo, B. M., \& Kashy, D. A. (1998). Everyday lies in close and casual relationships. Journal of Personality and Social Psychology, 74, 63-79.

DePaulo, B. M., Malone, B. E., Lindsay, J. J., et al. (2003). Cues to deception. Psychological Bulletin, 129, 74-118.

Eagly, A. (1987). Sex difference in social behavior: A social role interpretation. Hillsdale, NJ: Erlbaum.

Eagly, A. H., \& Wood, W. (1982). Inferred sex differences in status as a determinant of gender stereotypes about social influence. Journal of Personality and Social Psychology, 43, 915-928.

Eagly, A. H., Wood., W. \& Diekman., A. B. (2000). Social role theory of sex difference and similarities: A current Appraisal. In T. Eckes. \& H. M. Trautner (Ed), The Developmental Social Psychology of Gender (pp 123-174). Mahwah, NJ: Erlbaum.

Eckes, T., \& Trautner, H. M. (2000). The developmental social psychology of gender. Mahwah, NJ: Erlbaum.

Fletcher, J. O., \& Simpson, J. A. (2000). Ideal standards in close relationships: Their structure and functions. Current Directions in Psychological Science, 9, 102-105.

Gordon, A. K., \& Miller, A. G. (2000). Perspective differences in the construal of lies: Is deception in the eye of the beholder? Personality and Social Psychology Bulletin, $26,46-55$.

Gottman, J. M., \& Levenson, R. W. (1988). The social psychophysiology of marriage. In P. Noller \& M. Fitzpatrick (Eds.), Perspectives on marital interaction (pp. 182200). Philadelphia: Multilingual Matters Ltd.

Hall, J. A. (1979). Gender effects in deconding nonverbal cues. Psychological Bulletin, 85, 845-857.

Hample, D. (1980). Purpose and effects of lying. Southern Speech Communication Journal, 46, 33-47. 
Ivy, P. K., \& Backlund, P. (1994). Exploring gender speak: personal effectiveness in gender communication. New York: McGraw-Hill.

Kaplar, M. E., \& Gordon, A. K. (2004). The enigma of altruistic lying: Perspective differences in what motivates and justifies lie telling within romantic relationships. Personal Relationships, 11, 489-507.

Klein, W. M., \& Kunda, Z. (1992). Motivated person perception: Constructing justification for desired beliefs. Journal of Experimental Social Psychology, 28, 145168.

Knapp, M. L., \& Comadena, M. D. (1979). Telling it like it isn't: A review of theory and research on deceptive. Human Communication Research, 5, 270-285.

Levine, T. R., \& McCornack, S. A. (1992). Linking love and lies: A formal test of the McCornack and Parks model of deception detection. Journal of Social and Personal Relationships, 9, 143-154.

Linskold, S., \& Walters, P. S. (1983). Categories for acceptability of lies. Journal of Social Psychology, 120, 129-136.

Lippard, V. (1988). Ask me no questions I will tell you no lies: Situational exigencies for interpersonal deception. Western Journal of Speech Communication, 52, 91-103.

McCornack, S. A. (1997). The generation of deception messages: Laying the groundworks for a viable theory of interpersonal deception. In J. O. Green (Ed.), Message production: Advances in communication theory (pp. 91-126), Mahwah, NJ: Erlbaum.

McCornack, S. A., \& Levine, T. R. (1990). When lies are uncovered: Emotional and relational outcome of discovered deception. Communication Monographs, 57, 119. 138.

McCornack, S. A., \& Parks, M. R. (1986). Deception detection and relationships development: The other side of truth. In M.L. McLaughlin (Ed.), Communication Yearbook 9 (pp. 377-389). Beverly Hills, CA: Sage Publication.

Metts, S. (1989). An exploratory investigation of deception in close relationships. Journal of Social and Personal Relationships, 6, 159-179.

Miles, R. (1985). Women and Power. In N. Bernards \& T. O'Neill (Eds), Male/Female roles (pp. 70). San Diego, CA: Greenhaven Press.

Miller, G. R. (1976). Toward a new psychology of women. Boston: Beacon.

Miller, G. R., \& Stiff, J. B. (1992). Applied issues in studing deceptive communication. In R. S. Feldman (Eds), Application of nonverbal behavioral theories and research (pp. 217-237). Hillsdale, New Jersey: Lawrence Erlbaum associates. 
Miller, G. R., Mongeau, P.A., \& Sleight, C. (1986). Fudging with friends and lying to lovers: Deceptive communication in personal relationships. Interpersonal Politics and Conversational Management, 6, 210-220.

O’Hairy, H. D., \& Cody, M. J., (1987). Gender and vocal stress differences truthful and deceptive information sequences. Human Relations, 40, 1-14.

O’Hairy, H. D., \& Cody, M. J. (1994). Deception. In W. R. Cupach \& B. H. Spitzberg (Eds), The dark side of interpersonal communication (pp. 180-213). Hillsdale, NJ:

Erlbaum.

Paulhus, D. L. (2002). Socially desirable responding: The evolution of a construct. In H.I.Braun (Ed.), The role of constructs in psychological and educational measurement (pp. 49-69). Mahwah, NJ: Erlbaum.

Pearson, J. C., West, R. L., \& Turner, L. H. (1995). Gender and communication. Madison, WI: Brown \& Benchmark.

Rosenthal, R., Hall, J. A., DiMatteo, M. R., Rogers, P. L., \& Archer, D. (1979). Sensitivity to nonverbal communication: The PONS test. Baltimore, MD: Johns Hopkins Univerisy Press.

Sagrestano, L. M., Heavey, C.L., \& Christenses, A. (1997). Sex differences and similarities in communication. In D. J. Canary, \& K. Dindia (Eds.) Theoretical approaches to understanding sex differences and similarities in conflict behavior (pp. 287-302). New Jersey: Lawrence Erlbaum.

Saxe, L. (1991). Lying: Thoughts of an applied social psychologist. American Psychologist, 46, 409-415.

Spence, J. T., Helmreich, R. L. (1978). Masculinity \& femininity. Their psychological dimensions correlates, \& antecedents. Austin, TX: University of Texas Press.

Steier, J. S., Bruschke, J., \& Bai, C. (2002). The acceptability of deception as a function of perceivers' culture, deceiver's intention, and deceiver-deceived relationship. Western Journal of Communication, 66, 158-180.

Stiff, J. B., Kim, H. J., \& Ramesh, C. N. (1992). Truth biases and aroused suspicion in relational deception. Communication Research, 19, 326-345.

Tannen, D. (1994). Gender and discourse. New York: Oxford University Press.

Turner, R. R., Edgey, C., \& Olmstead, G. (1975). Information control in conversation: Honesty is not always the best policy. Kansas Journal of Sociology, 11, 69-89.

Wood, W., \& Karten, S. J. (1986). Sex differences in interaction style as a product of perceived sex differences in competence. Journal of Personality and Social Psychology, 50, 341-347. 
Zuckerman, M., DePaulo, B. M., \& Rosenthal, R. (1981). Verbal and nonverbal communication of deception. In L. Berkowitz (Ed), Advances in experimental social psychology (pp. 1-59). New York, NY: Academin Press. 